Among the 21 csDMARDs molecules: 8 (38\%) has been withdrawn, 4 (19\%) are already labelled in RA (hydroxychloroquine, leflunomide, methotrexate and sulfasalazine) and $9(43 \%)$ are in development: $1(11 \%)$ is in phase $1 / I I, 5(56 \%)$ in phase II, $3(33 \%)$ in phase IV.

Among the 117 bDMARDs molecules: 69 (59\%) has been withdrawn, 9 (8\%) are labeled in RA (abatacept, adalimumab, anakinra, certolizumab, etanercept, golimumab, infliximab, rituximab, sarilumab, tocilizumab) and $39(33 \%)$ are in development: $9(23 \%)$ in phase I, $3(8 \%)$ in phase I/II, $21(54 \%)$ in phase II, 5 $(12 \%)$ are in phase III, $1(3 \%)$ in phase IV. bDMARDs currently under development target B cells $(n=4)$, T cells $(n=2), T / B$ cells costimulation $(n=2)$,TNF alpha $(n=2)$, Interleukine 1 or his receptor $(n=3)$, Interleukine 6 or his receptor $(n=7)$, Interleukine $17(n=4)$, Interleukine $23(n=1)$, GM-CSF $(n=1)$, other cytokines or chemokines $(n=5)$, integrins or adhesion proteins $(n=3)$, interferon receptor $(n=1)$ and various other targets $(n=4)$.

Among the 105 tsDMARDs molecules: 64 (61\%) has been withdrawn, $6(6 \%)$ JAK inhibitors, have just been or will probably soon be labelled (baricitinib, filgotinib, peficitinib, tofacitinib and upadacitinib), 35 (33\%) are in development: $8(24 \%)$ in phase I, $26(74 \%)$ in phase II, $1(3 \%)$ in phase III and. tsDMARDs currently under development target tyrosine kinase $(n=12)$, janus kinase (JAK) $(n=3)$, sphingosine phostate $(n=3)$, PI3K pathway $(n=1)$, phosphodiesterase-4 $(n=3)$ B cells signaling pathways $(n=3)$ and various other targets $(n=10)$.

Conclusion: A total of 242 therapeutic trials involving 243 molecules have been or are being evaluated in RA. This development does not always lead to new treatments since $141(58 \%)$ have already been withdrawn. Hopefully, some of the currently evaluated drugs will contribute to improve the therapeutic management of RA patients, requiring a greater personalization of therapeutic strategies, both in the choice of molecules and their place in therapeutic sequences.

Disclosure of Interests: Julien Blaess: None declared, Julia Walther: None declared, Jacques-Eric Gottenberg Grant/research support from: BMS, Pfizer, Consultant of: BMS, Sanofi-Genzyme, UCB, Speakers bureau: Abbvie, Eli Lilly and Co., Roche, Sanofi-Genzyme, UCB, Jean Sibilia: None declared, Laurent Arnaud: None declared, Renaud FELTEN: None declared DOI: 10.1136/annrheumdis-2020-eular.1124

\section{AB0333 CLINICAL AND ULTRASONOGRAPHIC RESPONSE TO SUBCUTANEOUS METHOTREXATE IN EARLY RHEUMATOID ARTHRITIS. PRELIMINARY RESULTS.}

L. R. Caballero Motta ${ }^{1}$, A. M. Anzola Alfaro ${ }^{1}$, L. A. Torrens Cid ${ }^{1}$, C. Y. Soleto ${ }^{1}$, B. Serrano Benavente ${ }^{1}$, I. Janta ${ }^{1}$, J. Molina Collada ${ }^{1}$, C. Gonzalez ${ }^{1}$,

I. Monteagudo ${ }^{1}$, J. M. Alvaro Gracia ${ }^{1}$, J. C. Nieto ${ }^{1}$. 'Gregorio Marañón Hospital, Rheumatology, Madrid, Spain

Background: Metotrexate (MTX) is usually the first line therapy for Rheumatoid Arthritis (RA) because of its favorable efficacy-toxicity ratio. However the exact mechanism and treatment response time in both a clinical and ultrasonographic setting are still uncertain

Objectives: To describe the clinical and ultrasound response to MTX during the first 6 months of treatment in early RA patients who started subcutaneous methotrexate as the first disease-modifying drug (DMARD).

Methods: Ongoing prospective cohort of patients with early RA (ACR-EULAR 2010 criteria), over 18 years and starting MTX-SC. Patients had a clinical and ultrasonographic evaluation at baseline, 1, 3 and 6 months. We collected demographic data, C-reactive protein [CRP], erythrocyte sedimentation rate [ESR], rheumatoid factor [FR], anti-citrullinated protein antibody [ACPA]), inflammatory activity indexes (DAS28esr and DAS28crp) and EULAR's response to treatment (delta value of -1.2 in DAS28 scores). Joints explored with ultrasound were elbows and wrists (radio-carpal and inter-carpal joint) counted as a single joint, 1st-5th metacarpophalangeal (MCF), proximal interphalangeal (IFP), knees, tibio-talar and subtalar joints and 2nd-5th metatarsophalangeal (MTF) joints. Bone erosions were evaluated in 2nd and 5th MCF, styloid, distal ulna and 5th MTF. Synovitis was graduated semi-quantitatively from 0 to 3 (OMERACT) and calculated on B mode and Doppler.

Results: 35 patients were included (mean age 61.2 years, $65.7 \%$ women) with a median of $0.8(+/-8)$ months delay to diagnosis. 34 patients $(97.1 \%)$ started $15 \mathrm{mg}$ MTX-SC/weekly. A higher DAS28esr was found in baseline data for the group that had a response by month 1 (DAS28esr baseline 5.5 vs $4.2 \mathrm{p}=0.01$ ), no other significant differences were found. During the first month, a significant response was achieved in 13 (41\%) patients and remission in $11(35 \%)$ (Table 1). 17 patients have $6^{\text {th }}$ month data. $11(64.7 \%$ ) have achieved EULAR response compared to baseline $(P=0.0005)$ out of which $7(54.5 \%)$ had already reached it by month 1 . A difference in MTX dose (month1 14.8 vs month6 $17.1 \mathrm{p}=0.003$ ) was found between month 1 and 6 , with no differences in disease activity. In the ultrasonographic baseline data; 8 patients $(22.9 \%)$ had erosions, with a mean of 2,75 erosions/patient (22 of the 280 locations). During the follow up the global rating lowered, with no differences in B mode but significant differences in Doppler at the 6 month mark (Table 2). As of this report, 10 patients $(28.5 \%$ ) had stopped MTX treatment due to lack on response or adverse effects and $8(22.9 \%)$ are waiting $6^{\text {th }}$ month evaluation.

Table 1. Baseline vs month 1

\begin{tabular}{lccc}
\hline & Baseline & Month 1 & P Value \\
\hline EULAR response & 0 & $13(41)$ & $\mathbf{0 . 0 0 0 0 5}$ \\
MTX Dose mg (SD) & $14.8(+/-0.8)$ & $14.8(+/-1.6)$ & 1 \\
Prednisone Dose mg(SD) & $5.9(+/-6.5)$ & $2.9(+/-3)$ & $\mathbf{0 . 0 2}$ \\
DAS28crp (SD) & $4.3(+/-1.5)$ & $3,4(+/-1.4)$ & $\mathbf{0 . 0 2}$ \\
DAS28esr (SD) & $(4.8(+/-1.5)$ & $3.7(+/-1.4)$ & $\mathbf{0 . 0 0 6}$ \\
Remission (DAS28<1.2) & $3(9.6)$ & $11(35.5)$ & $\mathbf{0 . 0 4}$ \\
\hline
\end{tabular}

Table 2. Ultrasound synovitis global rating.

\begin{tabular}{|c|c|c|c|c|}
\hline & $\begin{array}{c}\text { Baseline } \\
\mathrm{N}=35\end{array}$ & $\begin{array}{c}1 \text { month } \\
\mathrm{N}=31\end{array}$ & $\begin{array}{c}3 \\
\text { months } \\
\mathrm{N}=25\end{array}$ & $\begin{array}{c}6 \\
\text { months } \\
\mathrm{N}=17\end{array}$ \\
\hline B Mode: Median (interquartile range) & $8(3.5-12)$ & $8(3-12.5)$ & $6(4-11)$ & $\begin{array}{c}5(2-11) \\
\text { p } 0,16\end{array}$ \\
\hline Doppler Mode: Median (interquartile range) & $2(0.5-6)$ & $2(0-6)$ & $2(0-6)$ & $\begin{array}{c}0(0-2) \\
\text { p } 0,005\end{array}$ \\
\hline
\end{tabular}

Conclusion: In this cohort half of the patients that responded to treatment had achieved this by month 1. A higher baseline inflammatory profile was related to the response. Little difference is found between month 1 and 6 on clinical data however ultrasonographic results suggest that at least 6 months are needed for Doppler improvement. Perhaps MTX has a faster effect over joint pain and low ers DAS28 scores requiring longer to completely suppress inflammatory activity. References:

[1] Braun, J. et al. Comparison of the clinical efficacy and safety of subcutaneous versus oral administration of methotrexate in patients with active rheumatoid arthritis. Arthritis Rheum 2008

Disclosure of Interests: Liz R. Caballero Motta: None declared, Ana Melissa Anzola Alfaro: None declared, Luis A Torrens Cid: None declared, Christian Y Soleto: None declared, Belén Serrano Benavente: None declared, lustina Janta: None declared, Juan Molina Collada: None declared, Carlos Gonzalez Consultant of: Gilead, Janssen, Novartis,, Speakers bureau: Abbvie, Celgene, Gilead, Janssen, Novartis, Pfizer, Roche, Indalecio Monteagudo: None declared, Jose Maria Alvaro Gracia: None declared, Juan Carlos Nieto Speakers bureau: Pfizer, Abbvie, MSD, Novartis, Janssen, Lilly, Nordic Pharma, BMS, Gebro, FAES Farma, Roche, Sanofi

DOI: 10.1136/annrheumdis-2020-eular.6573

\section{AB0334 COST-EFECTIVENESS OF JAK INHIBITORS IN RHEUMATOID ARTHRITIS IN THE REAL WORL PRACTICE}

A. Calvo Garcia ${ }^{1}$, N. García Castañeda ${ }^{2}$, C. Valero², I. Llorente ${ }^{2}$, B. Varas ${ }^{3}$, A. García-Vadillo ${ }^{2}$, I. González-Álvaro ${ }^{2}$, A. Morell ${ }^{1}$, E. Ramirez ${ }^{1}$, R. Garcia de Vicuna ${ }^{2}$ on behalf of HUP IMID Therapy Unit. ${ }^{1}$ University Hospital La Princesa, IIS-IP, Pharmacy, Madrid, Spain; ${ }^{2}$ University Hospital La Princesa, IIS-IP Madrid, Rheumatology, Madrid, Spain; ${ }^{3}$ University Hospital Santa Cristina, IIS-IP, Rheumatology, Madrid, Spain

Background: The Janus Kinase (JAK) inhibitors Baricitinib (BAR) and Tofacitinib (TOF), both in monotherapy or in combination with methotrexate, are indicated for moderate to severe active rheumatoid arthritis (RA) with inadequate response to conventional synthetic disease modifying anti-rheumatic drugs (csDMARD). Data about cost-effectiveness in a real-world setting are still scarce.

Objectives: To assess the cost-effectiveness $(\mathrm{C}-\mathrm{E})$ of BAR and TOF in patients with RA in usual clinical practice.

Methods: Retrospective observational study of adult RA patients who started BAR and TOF between September 2017 and December 2019, in a university hospital. Data were collected from the electronic medical records and the Dominion $®$ External Patient Dispensing program. Demographic, clinical and laboratory parameters [erytrocyte sedimentation rate (ESR), C reactive protein (CRP), Rheumatoid factor (RF), anti-citrullinated peptide antibodies (ACPA)], concomitant csDMARD, previous biological (b) DMARD, DAS28-ESR activity score items, and treatment duration were registered. DAS28-ESR remission o low disease activity (LDA) were used as the effectiveness measure to estimate $\mathrm{C}-\mathrm{E}$. The official Spanish prices were considered to calculate the costs of the treatments. Statistical analysis was performed with SPSS v. 15 program. Descriptive statistics are shown in proportions, medians and interquartile ranges (IQR) 